\title{
ADAPTING
}

PROGRAMMING TO AN URBAN ENVIRONMENT IN PAKISTAN 
Programme information

\begin{tabular}{l|l}
\hline Name & Improving Urban WASH Governance and Accountability \\
\hline Country & Pakistan \\
\hline Budget & €630,000 \\
\hline Start Date & April 2015 \\
\hline End Date & March 2019 \\
\hline Donors & Projects Direct (Oxfam) \\
\hline
\end{tabular}

\section{Problem analysis}

Pakistan is urbanizing rapidly, with over 38 percent of its population of 65 million currently living in a city, ${ }^{1}$ a figure which is expected to rise to nearly 50 percent over the coming 15 years. $^{2}$ Urbanization in Pakistan is driven by both endogenous population growth and an ongoing process of rural-urban migration as increasing numbers leave the countryside seeking a better life. While cities provide jobs and opportunity for many, they are also nexuses of inequality and have struggled to grow with their populations. In Pakistan, 45 percent of the urban population live in slums, ${ }^{3}$ defined by UN-Habitat as urban households lacking one or more of the following: access to improved water supplies, access to improved sanitation, sufficient-living area, durable housing and secure tenure. ${ }^{4}$

Water, sanitation and hygiene (WASH) needs remain a priority, with around 18 percent of the total urban population lacking improved sanitation, ${ }^{5}$ and 6 percent lacking access to improved water la figure which has steadily grown since 1990). ${ }^{6}$ These numbers, represented as percentages, downplay the vast number of individuals affected by inadequate supply, and fail to account for the quality of household connections to sewerage and water networks. Additionally, and particularly problematic in an urban environment, is the challenge of solid waste. The percentage of people residing in urban areas with access to regular waste collection was only 53 percent in 2013 . $^{7}$

At the city level, solutions to these challenges far exceed the capacity of a single organization such as Oxfam to address them directly. The capacity and mandate of local government actors have been, by the Government of Pakistan's own admission, inadequate in addressing issues at a local level. ${ }^{8}$ While moves have been made to improve governance structures, long periods of underinvestment at a local level have created gaps that are still being addressed.

This need for good governance has been reinforced by Oxfam's experience that issues in an urban context are frequently cross-cutting, interrelated and do not fit comfortably within single sector programming - see In Focus. Oxfam's 2014 desk review on urbanization in Pakistan identified a range of major interrelated issues, which extend beyond and overlap with water and sanitation management, namely: a rise in informal settlements; increasing urban poverty; the denial of women's rights - a particular problem in informal employment; social exclusion and marginalization of migrant and minority populations; rising urban food insecurity; and a lack of policy and action on disaster preparedness. ${ }^{9}$

\section{Brief programme description}

The current iteration of the programme began in 2015 and will run until March 2019, with a budget of $€ 630,000$. The programme has traditionally had a strong WASH focus, but is transitioning to a model that addresses challenges caused by urban poverty and inequality in a more holistic manner. It seeks to tackle issues from the top down - working on national-level policy issues in partnership with the Government of Pakistan, UN-Habitat and others; and from the bottom up, empowering citizens to be effective advocates for their rights, and to strengthen social accountability at a local level.

The programme seeks to ensure that women, men and young people living in poverty in cities in Sindh and Punjab provinces of Pakistan have improved access to decent income opportunities and a dignified, healthy habitat. To achieve this goal, the programme is structured around three pillars: bringing together citizens to contribute to local governance; improving the responsiveness and capacity of local government actors; and improving access to WASH services and livelihood opportunities.

The approach entails bringing together citizens in Effective Citizen Groups (ECG), with sub-groups for trade, WASH and participatory monitoring. Groups are supported in developing influencing strategies, and in lobbying local officials for improved WASH and livelihoods outcomes le.g. repair of water and sanitation networks, increased access to livelihood support services) through participation in, and monitoring of, local government planning processes.

The core mechanism for this process is the Urban Participatory Influencing and Development Plan (UPIDP), documents developed by ECGs that outline critical issues for the group and citizen-prioritized strategies for their resolution. The UPIDP is a lobbying tool that can be presented to local government 


\section{ADAPTING PROGRAMMING TO AN URBAN ENVIRONMENT IN PAKISTAN}

officials for action; it is also a benchmark against which progress can be measured. A small fund is also available to match-fund implementation of activities under each ECG's UPIDP on a co-financing basis. In order to monitor, implement and ensure accountability another group - a Participatory Monitoring and Evaluating group lcomprising ECG

representatives, local government and civil society actors) - is formed at the district level. This group is trained on social accountability laws ${ }^{10}$ to promote the accountability of duty-bearers, including their rights in regard to the constitution and freedom of information, and their rights as consumers and/or women.

Oxfam has also designed a government-owned online portal, ${ }^{11}$ which incorporates an information collection and management system to input into evidence-based decision making and provide opportunities for influencing the decision making process - see Innovation. 


\section{Achievements and challenges}

\section{Achievements to date}

\section{Bridging gaps between citizens and different levels of government}

Oxfam has used its programming to build bridges between citizens and government at a local hamlet level through ECGs. The programme scaled up connections, creating linkages between the often disjointed layers of government in Pakistan. The programme has also been successful in ensuring priorities expressed by citizens in hamlets are raised through union councils and ultimately reach district-level budgeting and planning. In a number of cases, ECGs have engaged in the democratic process directly, and have had members elected to local governance bodies, increasing the voice of citizens in budgeting and planning.

\section{Strengthening accountability through performance monitoring}

Monitoring of duty-bearers has seen concrete outcomes in terms of accountability. In Tehsil Municipal Administration in the city of Muzaffargarh, municipal solid waste collection had been characterized by poor service delivery, high levels of fraud (through the use of 'ghost workers') and high levels of absenteeism in staff. Monitoring by the local ECG documented these problems and their impact on service provision, enabling a successful campaign for the overhaul of the responsible department.

\section{Engaging in national-level dialogue}

Oxfam has recently been recognized by the government and UN-Habitat for its work supporting grassroots advocacy, and has been included on the National Habitat Steering Committee to support the government in developing a new urban agenda for the forthcoming National Urban Policy. This role provides Oxfam, its partners and the citizens it supports with a powerful tool for influencing urban development at a much larger scale beyond the programme.

\section{Inclusion}

The programme has worked to ensure that ECGs are inclusive, and has worked hard to promote engagement by women and young people, ensuring a broad cross section of voices are heard, and that the needs of all citizens supported under the programme have been addressed. Women have played a strong role within the ECGs, and have been among the ECG members who have stood for election to their elected bodies.

Additionally, at least one ECG has welcomed the participation of a transgender woman, who has praised the group for raising her status in the community. In an interview with Oxfam, she described the transformative effect working with the group has had: 'The ECG has returned my respect in society. Today, I sit alongside doctors, engineers and lawyers as an equal.'

\section{Innovation}

\section{ICT, accountability and sustainability}

As part of its support to the capacity building of local authorities, Oxfam has deployed information management tools to map, and make public, land-use data for the city of Muzaffargarh. The programme has supported local authorities in fulfilling their responsibilities under the Land Use Reclassification Act, by providing a platform for the consolidation and analysis of land-use data le.g. transport, land use and population surveys). The platform was made public, and became a useful tool in advocating for risksensitive, multi-year, scenario-based land-use planning; and for supporting the development of water and sanitation management plans for cities and municipalities.

At the time of writing however, the government-hosted platform, which encompasses the entirety of the internet presence of the administration, is currently offline, a consequence of non-payment to a service provider by the local authority. Key learning from the programme has been that IT infrastructure must be approached in the same way as any 'hardware' project, and that clear roles, responsibilities and financing must be in place for software platforms to be sustainable.

\section{Specific challenges}

Operating within an urban context brings a new range of challenges and opportunities. Organizations such as Oxfam must reconsider previous assumptions about scale, community, responsibility, the sectors that frame its programming, and the policies and roles of donors.

\section{Lessons learned}

Plan for sustainability in IT infrastructure in the same way as would be done for any hardware project.

The urban environment changes the way programmes have to think about many things, including partnership. 


\section{Partnerships}

\section{Partnerships}

Working within an urban context requires new ways of thinking about and managing partnerships. International NGOs, such as Oxfam, are comparatively new as actors in cities. The organizations that do exist are often of a different profile to those with which Oxfam typically works, and have required extensive capacity building on participatory methodologies and institutional strengthening.
Within cities there is, however, a greater scope for cooperation with non-traditional actors, particularly with the private sector. The programme has explored opportunities for private sector cooperation, but has found that working with such actors has been a learning process, and that some of Oxfam's tools for partnership may need to be adjusted to facilitate such partnerships in the future. 


\section{In focus}

\section{Adapting programming to an urban environment}

\section{Scale and impact}

When working in a village, populations are small, and it's pretty easy to ensure that you're reaching most people. This simply doesn't work in a city', explains Dr. Hasnain Ali, Oxfam's Urban Programme Manager in Pakistan. 'We have a limited budget, and with a population of concern in the hundreds of thousands, you quickly realize that it's not possible to work in the same way.'

To ensure impact at scale in Pakistan, the programme has a strong governance and social accountability focus. Oxfam has worked to support citizens in engaging with planning and budgeting processes, and in monitoring their implementation. This approach, through which we convene and facilitate local networks to effect change, has the potential for far greater reach than 'direct implementation'. It is also more costeffective when approaching challenges at scale, as it utilizes existing (i.e. government) resources - ensuring municipal activity is targeted where it will have the greatest impact.

The programme contains a 'hardware component', which has been useful in ensuring buy-in from citizens' groups and local government actors. However, infrastructure development has been limited, and has operated on the basis of a 'start-up fund', which leverages contributions from local government and communities to kick-start activities. Here Oxfam serves as a catalyst for change, as opposed to a manager.

\section{New conceptions of 'community'}

In a rural setting, a 'community' is generally well understood. It is easily identifiable and can be subdivided along relatively simple lines (e.g. family, religious affiliation etc.). Urban communities are far more diverse and fragmented. Individuals might feel more affinity with their profession or subculture than with someone living in the same building.

Cities are highly individualistic compared to their rural counterparts, and in this context, approaches to traditional community mobilization must be rethought. The programme has addressed this challenge by using the effective citizen, as opposed to the community, as the key unit of analysis. The approach has been challenging, with the establishment of groups being more difficult than in rural settings, where interventions often build on pre-existing structures. It has also created opportunities, with the programme's ECGs being typically more diverse and less centralized than traditional community groups.

\section{Responsibility: ownership and coordination}

The urban context presents new challenges in relation to responsibility for change. At a household level, the majority of the urban poor live in rented accommodation or informal settlements, which diminishes ownership and the sense of responsibility for an environment. Households have limited resources and little incentive to prioritize work on infrastructure they do not feel they own. They may also rightly feel that responsibility lies with duty-bearers (i.e. landlords, municipal authorities).

At a municipal level, however, ownership and responsibility is complex, overlapping and fragmented. Large numbers of agencies, authorities and actors must be consulted before a simple construction project can be undertaken.

Oxfam's role in this context is to mediate between all stakeholders with an interest in local development: ensuring citizens are aware of their rights and responsibilities, and supporting lobbying of duty-bearers for change, while simultaneously supporting local authorities in pushing forward a project, seeking buy-in at all levels.

\section{Interconnected issues and meeting expectations}

Early learning from the programme was that once assembled, ECGs' interests rapidly went well beyond the WASH entry point. As noted previously, urban programming requires a holistic approach, which transcends traditional sectors. From livelihoods, rights in the informal economy and tariffs for service provision, to land rights and disaster management capacity, issues in an urban context are more greatly interrelated and cannot be tackled in isolation.

Expectations from groups are also higher, and the timeframes within which change is anticipated are shorter. Oxfam's model, by necessity, works on a governance and planning level; however, citizens represented in ECGs have a strong focus on service delivery, which demands rapid action - something that duty-bearers are not always capable of delivering on. Expectation management and mediation between citizens and duty-bearers has thus been a key part of programming.

\section{Working with donors}

Both implementing agencies and donors are learning with regard to the urban environment. Many donors, particularly larger organizations, continue to be focused on large-scale infrastructure projects, which while undeniably valuable, ignore the lessons learned outside the city on community engagement in development programming for ownership and sustainability.

Oxfam's work in Pakistan has, as described above, used hardware only as a catalytic factor, with focus instead on mobilization, facilitation and policy. In budgetary terms, this has led to projects that are by necessity 'staff heavy', which have less appeal to donors seeking a larger 'programme' component.

\section{For further information about this programme: www.oxfam.org.uk/wash-pakistan}




\section{ADAPTING PROGRAMMING TO AN URBAN ENVIRONMENT IN PAKISTAN}

\section{Notes}

${ }^{1}$ World Bank. (2015a). Urban population (\% of total). United Nations Population Divisions World Urbanization Prospects. Retrieved from http:// data.worldbank.org/indicator/SP.URB. TOTL.IN.ZS?locations=PK. Accessed 30/03/2016.

${ }^{2}$ World Bank. (2016). Health and Nutrition Population Statistics: Population Estimates and Projections. Retrieved from http:// databank.worldbank.org/data/reports.

aspx?source $=$ Health $\% 20$ Nutrition $\% 20$ and $\% 20$ Population $\% 20$ Statistics:\%20Population\%20estimates\%20and\%20 projections. Accessed 30/03/2016.

${ }^{3}$ World Bank. (2015b). Population living in slums, (\% of urban population). UN-Habitat, retrieved from the United Nation's Millennium Development Goals database. Data are available at: mdgs.un.org http://data.worldbank.org/indicator/EN.POP. SLUM.UR.ZS?locations=PK. Accessed 30/03/2016.

${ }^{4}$ Millennium Development Goals Indicators. (2000). Population living in slums, ( $\%$ of urban population), definition. Retrieved from https://mdgs.un.org/unsd/mdg/Metadata.

aspx? Indicatorld $=0 \&$ Series $\mid d=711$

${ }^{5}$ World Bank. (2015c). Improved sanitation facilities, urban $1 \%$ of urban population with access). WHO/UNICEF Joint Monitoring Programme (JMP) for Water Supply and Sanitation. Retrieved from http://data.worldbank.org/indicator/SH.STA.ACSN. UR?locations $=$ PK
${ }^{6}$ World Bank. (2015d). Improved water source, urban (\% of urban population with access). WHO/UNICEF Joint Monitoring Programme (JMP) for Water Supply and Sanitation. http:/ / data. worldbank.org/indicator/SH.H2O.SAFE.UR.ZS?locations=PK

${ }^{7}$ Government of Pakistan, Ministry of Climate Change. (2015). National Report for HABITAT III. June 2015. Retrieved from http:// habitat3.org/wp-content/uploads/Pakistan-Final-inEnglish.pdf

${ }^{8} \mathrm{lbid}$, pages $40-41$

${ }^{9}$ Hasan, Arif and Khan, Faisal S. (2014). Urbanization in Pakistan: A Synthesis and Policy Options Study for Urban Programming.

${ }^{10}$ District Government of Muzzafargarh. Services and Laws. http://muzaffargarh.gop.pk/services-laws/

${ }^{11}$ District Government of Muzzafargarh. http:// muzaffargarh. gop.pk/ 
This paper was written by lan Goodrich. Oxfam acknowledges the assistance of Dr Syed Hasnain Ali and Hashim Zaidi in its production. It is part of a series of papers written to inform public debate on development and humanitarian policy issues.

For further information on the issues raised in this paper please email hkuwabara@oxfam.org.uk

This publication is copyright but the text may be used free of charge for the purposes of advocacy, campaigning, education, and research, provided that the source is acknowledged in full. The copyright holder requests that all such use be registered with them for impact assessment purposes. For copying in any other circumstances, or for re-use in other publications, or for translation or adaptation, permission must be secured and a fee may be charged. Email policyandpractice@oxfam.org.uk

The information in this publication is correct at the time of going to press.

Published by Oxfam GB for Oxfam International under ISBN 978-0-85598-988-0 in July 2017.

Oxfam GB, Oxfam House, John Smith Drive, Cowley, Oxford, OX4 2JY, UK.

\section{Oxfam}

Oxfam is an international confederation of 20 organizations networked together in more than 90 countries, as part of a global movement for change, to build a future free from the injustice of poverty. Please write to any of the agencies for further information, or visit www.oxfam.org

Cover photo: Timothy Allen/Oxfam 